\title{
Algorithms to prescribe Schroth exercises for each of four Schroth curve types
}

\author{
EM Watkins ${ }^{1 *}$, S Bosnjak', EC Parent ${ }^{2}$ \\ From 8th International Conference on Conservative Management of Spinal Deformities and SOSORT 2011 \\ Annual Meeting \\ Barcelona, Spain. 19-21 May 2011
}

\section{Background}

Systematic reviews have shown that most exercise studies for scoliosis treatment lacked standardization of exercise prescription. Schroth exercise prescription is based on scoliosis curve type with specific exercises designed to target different aspects of the spinal curve and different areas of the body. The intensity of exercises is increased based on patient capacity. There may be dose dependant and exercise specific effects, therefore it is important to adopt a standardized method of prescription, especially in clinical research trials.

Goal: To describe prescription algorithms and a performance checklist for standardizing Schroth exercise treatment based on instructions in the Schroth training.

\section{Materials and methods}

Prescription algorithms to guide progression in intensity and from isometric to dynamic exercises were developed by two Schroth-certified therapist-researchers and a physiotherapy professor. Intensity increases by dosage and by exercise type - from gravity assisted postural shifts to active postural shifts against gravity. The performance checklist was developed to ensure adequate exercise performance based on key Schroth principles of breathing and autocorrection.

\section{Results}

An exercise prescription algorithm has been designed for each of the four Schroth curve types. The patient begins with the "Sitting-on-a-ball" exercise. If performance assessed using the proposed checklist is adequate, the next exercise in the algorithm is attempted. Otherwise, the patient attempts the easier exercise. Adequate

${ }^{1}$ University of Alberta, Faculty of Rehabilitation Medicine Edmonton, Canada Full list of author information is available at the end of the article performance at start intensity as rated by the checklist, leads to dosage increase to target intensity.

\section{Conclusions}

The proposed algorithms and performance checklist will be used to standardize exercise prescription in a randomized control trial.

\section{Author details}

University of Alberta, Faculty of Rehabilitation Medicine Edmonton, Canada. ${ }^{2}$ University of Alberta/Alberta Health Services Edmonton, Canada.

Published: 27 January 2012

\section{doi:10.1186/1748-7161-7-S1-P22}

Cite this article as: Watkins et al:: Algorithms to prescribe Schroth

exercises for each of four Schroth curve types. Scoliosis 2012 7(Suppl 1): P22.
Submit your next manuscript to BioMed Central and take full advantage of:

- Convenient online submission

- Thorough peer review

- No space constraints or color figure charges

- Immediate publication on acceptance

- Inclusion in PubMed, CAS, Scopus and Google Scholar

- Research which is freely available for redistribution
() Biomed Central

\section{Biomed Central}

